\title{
Correction to: Collective aspirations: Collective regulatory focus as a mediator between transformational and transactional leadership and team creativity
}

\author{
Dina Van Dijk ${ }^{1} \cdot$ Ronit Kark ${ }^{2,3} \cdot$ Fadel Matta $^{4} \cdot$ Russell E. Johnson ${ }^{5}$ \\ Published online: 12 June 2020 \\ (C) Springer Science+Business Media, LLC, part of Springer Nature 2020
}

Correction to: J Bus Psychol. https://doi.org/10.1007/s10869-020-09692-6

In the original manuscript, the model presented in figs. $1 \& 2$ erroneously depicted both mediating variables as "Promotion collective regulatory focus". The second mediator should be "Prevention collective regulatory focus". There are no changes in the main text nor in the dataset themselves. We apologize for any confusion that may have resulted.

The online version of the original article can be found at https://doi.org/ 10.1007/s10869-020-09692-6

Dina Van Dijk

dinav@bgu.ac.il

Ronit Kark

karkronit@gmail.com

Fadel Matta

fmatta@uga.edu

Russell E. Johnson

johnsonr@broad.msu.edu

1 Department of Health Systems Management, Ben-Gurion University of the Negev, Beer-Sheva, Israel

2 Department of Psychology, Bar-Ilan University, Ramat Gan, Israel

3 Business School, Exeter University, Exeter, England

4 Department of Management, University of Georgia, Athens, GA, USA

5 Department of Management, Michigan State University, East Lansing, MI, USA
2. The second author Ronit Kark has additional affiliation "Exeter University".

3. Acknowledgment: "This study was supported by the Israel Science Foundation (Grant No. 254/07)"

Publisher's Note Springer Nature remains neutral with regard to jurisdictional claims in published maps and institutional affiliations. 


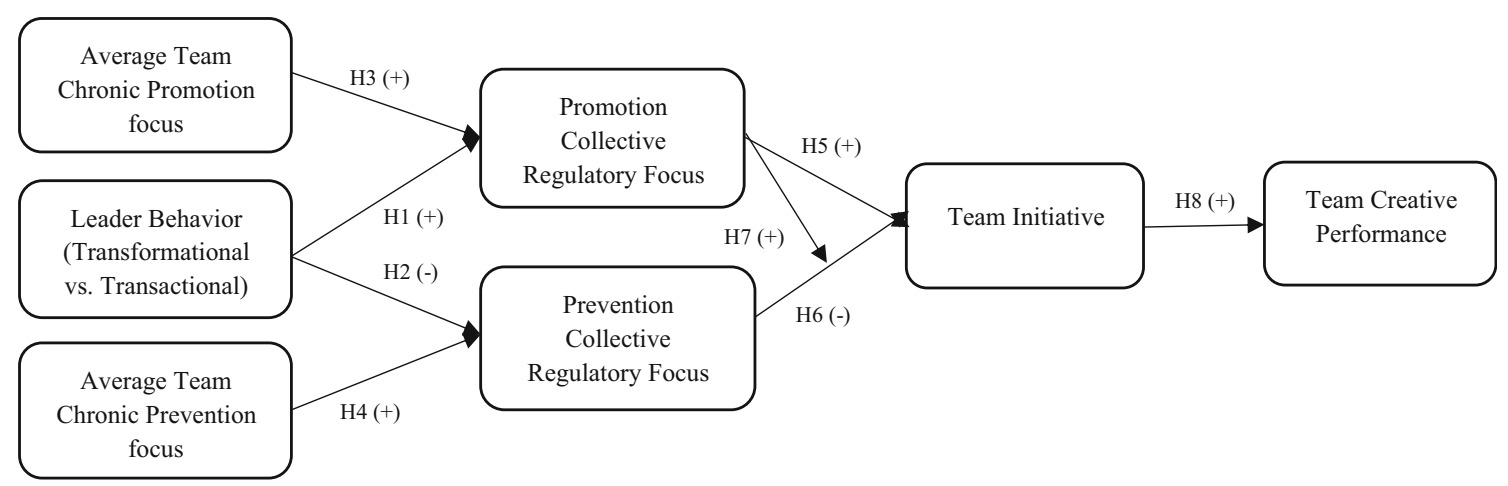

Fig. 1 Hypothesized Mode

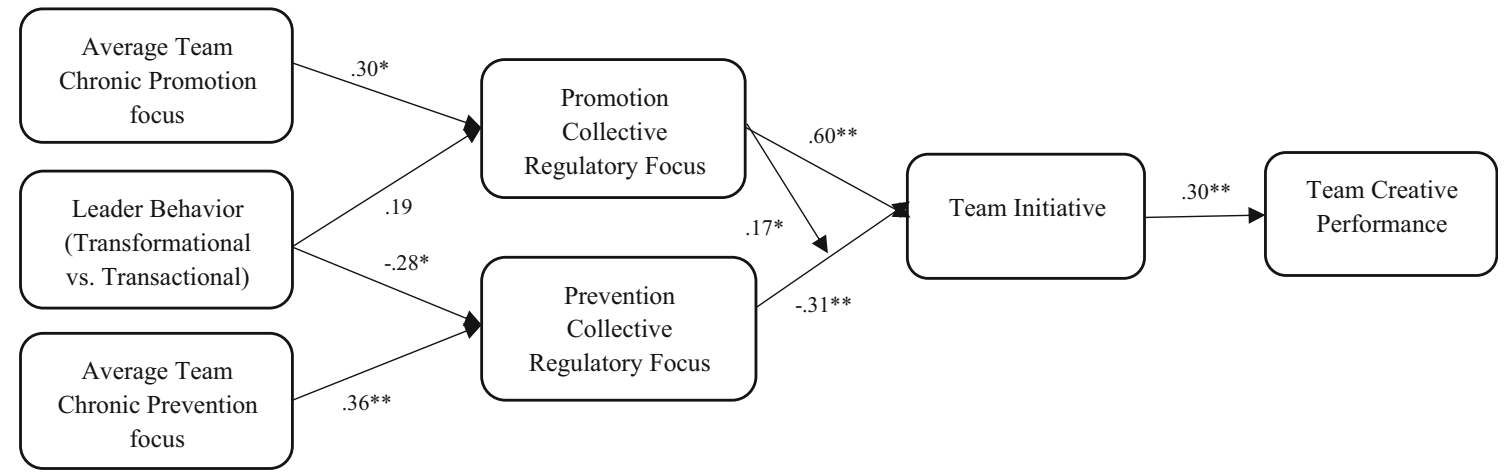

Fig. 2 Results of Path Analysis (Study 1) Note: $\mathrm{n}=49$ teams. $\chi^{2}(15)=$ disturbances of each of the component terms. Standardized coefficients $15.982, p=.38 ; \mathrm{CFI}=.985 ; \mathrm{RMSEA}=.037$; $\mathrm{SRMR}=.105$. Leadership condition is coded $0=$ transactional leader behavior and $1=$ transformational leader behavior. The interaction was tested using a product term, and the disturbance of the product term was allowed to covary with the are presented. $\mathrm{R}^{2}$ for collective prevention focus was $21.7 \%$, collective promotion focus was $14.9 \%$, team initiative was $52.8 \%$, and creative performance was $8.6 \%$. * $p<.05, * * p<.01$ 